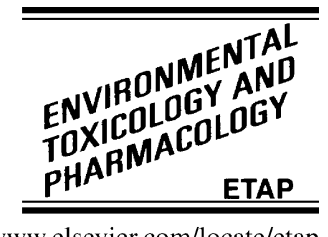

www.elsevier.com/locate/etap

\title{
Neurobehavioural investigations in adolescents exposed to environmental pollutants
}

\author{
Griet Vermeir ${ }^{\mathrm{a}}$, Mineke Viaene ${ }^{\mathrm{a}, \mathrm{b}, *}$, Jan Staessen $^{\mathrm{c}}$, Elly Den Hond ${ }^{\mathrm{c}}$, Harry A. Roels ${ }^{\mathrm{d}}$ \\ ${ }^{a}$ Neurotoxicology Expertise Center, Flemish Agency for Mental Health, Pas 200, 2440 Geel, Belgium \\ ${ }^{\mathrm{b}}$ Department of Occupational Health, Catholic University of Leuven, Kapucijnenvoer 35-5th Floor, 3000 Leuven, Belgium \\ ${ }^{\mathrm{c}}$ Departement of Molecular and Cardiovascular Research, Hypertension and Cardiovascular Revalidation Section, Catholic University of Leuven, \\ Onderwijs en Navorsing, UZ Gasthuisberg, Herestraat 49, 3000 Leuven, Belgium \\ d Unité de Toxicologie Industrielle et de Médecine du Travail, Université Catholique de Louvain, Clos Chapelle-aux-Champs 30.54, 1200 Brussels, Belgium
}

Available online 2 February 2005

\begin{abstract}
Environmental exposures to industrial pollutants have been associated with lowered intelligence and behavioural problems. The Flemish Environmental and Health Study focussed on biomonitoring of exposure and associated health effects.

This part of the study investigated neurobehavioural performance in adolescents in relation to lead (blood $\mathrm{Pb}$ ), cadmium (urine $\mathrm{Cd}$ ), polychlorinated biphenyls (PCB concentration of congeners 138, 153 and 180) and compounds with 'dioxin-like' activity (measured by the CALUX-assay). One-hundred and twenty girls and 80 boys (mean age 17.4 years) were enrolled. The NES battery was used to assess simple reaction time, switching attention, digit span forward, hand-eye coordination and symbol-digit substitution (SDS). Multiple regression analysis was performed to study dose-effect relationships between the neurobehavioural outcome variables and the exposure parameters in boys and girls. Slowing of SDS with increasing $\log \mathrm{PbB}$ and $\log \mathrm{CdU}$ was seen in boys only (PbB 39-1549 $\mathrm{nmol} / \mathrm{L}, \mathrm{CdU} 0.02-0.40 \mathrm{nmol} / \mathrm{mmol}$ creatinine). No dose-effect relations were found with serum PCB concentrations or CALUX-TEQs. Only one of several tests showed a performance decrease related to given environmental exposures to heavy metals. Further studies are needed to clarify whether the pattern of results reflects gender effects or the different exposure characteristics of boys and girls in our study.
\end{abstract}

(C) 2005 Published by Elsevier B.V.

Keywords: Polychlorinated biphenyls (PCBs); Lead (Pb); Cadmium (Cd); Neurobehavioural function; Environment; Adolescents

\section{Introduction}

Exposure to environmental contaminants such as heavy metals (e.g. lead and cadmium) and polychlorinated aromatic hydrocarbons (e.g. polychlorinated biphenyls) have been associated with diminished general intelligence, impaired visuomotor and cognitive ability development, and behavioural problems. Especially exposure to lead $(\mathrm{Pb})$, but also to cadmium $(\mathrm{Cd})$ may result in behavioural changes and intellectual deficits in young children as well as in adolescents, and to a lesser extent in adults (Struempler et al., 1985; Feldman, 1999; Burns et al., 1999; Viaene et al., 2000). Concurrent exposure to other heavy metals is relatively common (e.g. Cd,

\footnotetext{
* Corresponding author. Tel.: +32 14/579111.

E-mail address: m.k.viaene@opzgeel.be (M. Viaene).
}

mercury) and it could result in a more pronounced cognitive decline (Lewis et al., 1992). Although the effects of very low environmental exposure to $\mathrm{Pb}$ (blood $\mathrm{Pb}<10 \mu \mathrm{g} / \mathrm{dL}$ ) is most probably negligible, the threshold below which there is an insignificant influence of $\mathrm{Pb}$ exposure in children is still uncertain (Pocock et al., 1994; Canfield et al., 2003).

Prenatal exposure to PCBs and dioxins has also been associated with behavioural changes and poorer cognitive functioning in pre-school children. These effects were mostly limited to the non-breastfed group (Patandin et al., 1999). Effects on play behaviour were still measurable in school-aged children, although the cognitive and motor developmental delay did not persist for the full cohort (Vreugdenhil et al., 2002a,b).

As harmful effects of heavy metals and PCBs have been reported in many industrialized countries, a campaign of the Flemish Ministry of Health (Belgium) was set up in 1999 to 
assess regional differences in pollutant concentrations. The Flanders Environmental and Health Study (FLEHS) focused on biomonitoring of life time exposure (Nawrot et al., 2002) and health effects associated with these exposures in adolescent boys and girls. Immunological markers (Van Den Heuvel et al., 2002), sexual development (Den Hond et al., 2002), renal function and cytogenetic markers (Staessen et al., 2001) were investigated. The present study investigated neurobehavioural performance in adolescent boys and girls living in one rural and two suburban areas of Flanders in relation to life-time exposures to $\mathrm{Pb}, \mathrm{Cd}, \mathrm{PCBs}$ and compounds with 'dioxin-like' activity [Chemical Activated Luciferase gene eXpression bioassay (CALUX), Murk et al., 1996].

\section{Materials and methods}

Study design and analytical methods are described in detail by Staessen et al. (2001).

\subsection{Study population}

The participants were recruited from grammar schools in the study areas. The inclusion criteria were: (1) being a student of the last two years and (2) life-long residence in the area selected. Two hundred adolescents (mean age 17.4 years) who life-long lived in two polluted suburban areas $(n=100)$ or one rural area $(n=100)$ participated in this study. The suburban areas were located nearby a non-ferrous smelter and two (municipal and industrial) waste incinerators, a crematory, printingworks and various other industries. Both suburban locations are crossed by motorways that carry over 80,000 vehicles per day. Two groups, 80 boys and 120 girls, were enrolled in the study. The groups were matched for age and area. Group characteristics are summarised in Table 1.

\subsection{Questionnaires}

Questionnaires and neurobehavioural testing were administered during school time by trained nurses. Questionnaires included questions about the educational level of the adolescent (3 levels), smoking ( $0 / 1$, number of cigarettes), alcohol consumption $(0 / 1$, number of alcoholic beverages during the week and the weekends; alcohol abuse, i.e. >5 alcoholic beverages/day), illicit drug use (0/1), and motivation in performing the tests (\%, scored by marking a line running from 0 to 100\%). Ethanol consumption (g ethanol/week) was calculated. Self-administered questionnaires for parents inquired about tobacco, drug and alcohol consumption during pregnancy by the mother $(0 / 1)$, birth order of child, breastfeeding $(0 / 1)$, complications during pregnancy $(0 / 1)$, prematurity $(<38$ weeks, $0 / 1)$, divorce $(0 / 1)$ and social class (low/middle/high).

\subsection{Neurobehavioural test methods}

A computer assisted neurological test battery, the Neurobehavioural Evaluation System (NES, version 4.38) (Letz, 1991) was used. Time of testing (morning hours, afternoon hours) was permutated across boys and girls. The tests were performed in a quiet room, under supervision and with room temperatures monitored between 18 and $21^{\circ} \mathrm{C}$. Attention was assessed by the simple reaction time test (SRT) (mean reaction time in milliseconds on 80 stimuli presented at random intervals of 2.5-5 s) and the switching attention test (SWAT) [mean reaction time in msec to: (i) the location of an arrow on the screen (RT-location); (ii) the direction of the arrow (RTdirection); (iii) at random to the location (SWAT-location) or direction (SWAT-direction) of the arrow as indicated on the screen when the arrow appears]. The first two parts of the SWAT-test are measuring sustained attention, the third

Table 1

Group characteristics

\begin{tabular}{|c|c|c|}
\hline & Girls $(n=120)$ & Boys $(n=80)$ \\
\hline Residence (suburban/rural) & $60 / 60$ & $40 / 40$ \\
\hline Age & $17.4 \pm 0.8$ & $17.3 \pm 0.8$ \\
\hline Schooling level (low, moderate, high) & $34 / 75 / 11(28 \% / 63 \% / 9 \%)$ & $13 / 54 / 13(16 \% / 68 \% / 16 \%)$ \\
\hline Smokers & $31(26 \%)$ & $19(24 \%)$ \\
\hline Alcohol use & $35(29 \%)$ & $52(56 \%)$ \\
\hline Median alcohol use (range) (g ethanol/week) & $4.3(2.3-7.1)$ & $11.4(4.3-24.7)$ \\
\hline Drug use or alcohol abuse & $31(26 \%)$ & $16(20 \%)$ \\
\hline Motivation $(<70 \% / \geq 70 \%)$ & $7 / 113$ & $4 / 76$ \\
\hline Breastfeeding & $65(55 \%)$ & $48(61 \%)$ \\
\hline Complications during pregnancy or prematurity & $32(27 \%)$ & $18(23 \%)$ \\
\hline Tobacco or alcohol use by the mother during pregnancy & $31(26 \%)$ & $22(28 \%)$ \\
\hline Social class (low, moderate, high) & $31 / 60 / 9$ & $16 / 69 / 15$ \\
\hline Living in the family of origin & $104(87 \%)$ & $75(95 \%)$ \\
\hline $\mathrm{PbB}(\mathrm{nmol} / \mathrm{L})^{\mathrm{a}}$ & $79.43(9.55-363.08)$ & $107.15(38.90-1548.82)^{* * *}$ \\
\hline $\mathrm{CdU}(\mathrm{nmol} / \mathrm{mmol} \text { creatinine })^{\mathrm{a}}$ & $0.16(0.04-1.05)$ & $0.12(0.02-0.40)^{* * *}$ \\
\hline$\Sigma \mathrm{PCB}\left(\mathrm{pmol} / \mathrm{g}\right.$ serum lipids) ${ }^{\mathrm{a}}$ & $208.93(47.44-891.25)$ & $380.19(128.82-1108.05)^{* * *}$ \\
\hline TEQ (pg/g serum lipids) ${ }^{\mathrm{a}}$ & $30.90(3.39-138.04)$ & $36.31(1.86-231.72)^{\mathrm{NS}}$ \\
\hline
\end{tabular}

\footnotetext{
NS: $p>0.05$.

${ }^{a}$ Geometric means (range) are presented.

*** Student's $t$-test $p<0.001$.
} 
part of the test requires switching between two kinds of instructions (selective attention). Memory and attention were measured by the digit-span-forward test (EURONEST version, mean number of digits calculated from 20 consecutive trials) (Gilioli, 1993). Visuomotor performance was determined by the hand-eye coordination test (HEC) (expressed as the root mean squared error compared to the curve of the best out of seven trials) and by the symbol-digit substitution test (SDS) (average of the two fastest performances out of five trials, expressed in seconds).

\subsection{Exposure}

Historically the vicinity of the nonferrous smelter is known for its pollution with $\mathrm{Pb}$ and $\mathrm{Cd}$, while the environment of the suburban areas located nearby the waste incinerators were only monitored for dioxins. The rural area had no known industrial pollution. Across areas, mean ambient air concentration of toluene $\left(8.3 \mu \mathrm{g} / \mathrm{m}^{3}\right)$ and benzene $\left(1.5 \mu \mathrm{g} / \mathrm{m}^{3}\right)$ were very low and were not considered for further analysis.

To measure activity of 'dioxin-like' compounds, the Chemical Activated Luceferase gene eXpression bioassay (CALUX, Murk et al., 1996) was used. In contrast to the analysis of individual compounds of PCBs or polychlorinated dibenzo- $p$-dioxins (PCDDs) and furans (PCDFs), this bioassay needs only low volumes of serum and measures the binding of 'dioxin-like' compounds to the aryl hydrocarbon receptor (AhR). It has been shown that most of the toxic actions induced by 'dioxin-like' compounds (such as co-planar PCBs, PCDDs and PCDFs) are mediated by the AhR signal transduction pathway (Safe, 1990). Safe (1990) introduced the concept of 'dioxin-like' toxic equivalent factor (TEF), allowing conversion of the chemical data set into the AhR-related toxic potency of the mixture of individual 'dioxin-like' compounds. Concentrations of individual 'dioxin-like' compounds are multiplied by their respective TEF values and added together to give the 'dioxin-like' total toxic equivalency (TEQ). This concept is also used for the TEQ calculations of the WHO. The CALUX-bioassay has been developed to measure the total TEQ value of complex mixtures directly. The CALUX-based TEQs are calculated by comparing an AhR-controlled luciferase activity induced by the sample against a dose-response curve generated from 2,3,7,8-tetra-chlorodibenzo- $p$-dioxin (TCDD) concentration standards analysed simultaneous (Murk et al., 1996, see also Koppen et al., 2001). The dioxin congener TCDD is the reference compound for polychlorinated aromatic hydrocarbons, which include dioxins, PCBs, and polychlorinated dibenzofurans (Hansen, 1998). CALUX-TEQs have been reported in literature to have good correlations with total TEQs, (correlation coefficients up to 0.74 ), and is useful in population studies (Koppen et al., 2001).

In addition serum concentrations of the PCB congeners 138,153 , and 180 were measured as biomarkers of exposure to PCBs (Hansen, 1998) and summed (expressed as $\Sigma$ PCB in nmol/g serum lipids). The PCB analyses were performed at the Analytical Chemistry department of the Medical Institute of Environmental hygiene (Dusseldorf, Germany). The method was worked out and described by Fastabend (2000).

Blood $\mathrm{Pb}(\mathrm{PbB})$ and urinary $\mathrm{Cd}$ concentration $(\mathrm{CdU})$ were determined as well (for detailed description of environmental factors and analytical methods: see Staessen et al., 2001).

\subsection{Statistical analysis}

Distributions of the variables were checked and log-normal transformation was performed when needed (PbB, CdU, $\Sigma$ PCB, CALUX-TEQ).

The results of the attention tests (five outcome variables) were grouped by a factor analysis with four factors (eigenvalues $\geq 0.40$ taken into account, explained variance $=76 \%$ ). Factor 1 had very high loadings on all the attention variables (RT-location, RT-direction, SWAT-location, SWAT-direction). The other factors had either high loading on one test or were not congruent with available literature data (Emmen et al., 1998). Only individual factor scores for factor 1 ('factor attention') were calculated and used for further analysis. Additionally performance parameters of digit span forward (DSF), hand-eye coordination test (HEC) and symbol-digit substitution (SDS) were examined as dependent variable in the regression analyses.

Multiple linear regression analyses were performed to study dose-effect relationships between the neurobehavioural outcome variables and $\mathrm{PbB}$ or $\mathrm{CdU}$ in boys and girls separately. In addition, the groups were divided in a breastfed and non-breastfed group to study the effect of $\Sigma \mathrm{PCB}$ and CALUX-TEQ.

Covariable selection was based on a search of the literature (Medline, languages English, French, German, Dutch) on the topic of neurobehavioural tests and exposure parameters. Covariables which were reported to be important in neurobehavioural development of children or test results of adults were included (educational level of the adolescent, educational level of the mother, social class, living in the family of origin or not, birth order of the child, birth weight, complications during pregnancy/prematurity, tobacco/alcohol consumption by the mother during pregnancy, illicit drug use/alcohol abuse, smoking, and body mass index). They were all added in regression models by a forward-stepwise procedure. Dose-effect relationships between the neurobehavioural outcome variables and exposure parameters were tested in separate models, each including one exposure variable ( $\mathrm{PbB}, \mathrm{CdU}, \Sigma \mathrm{PCB}$ or CALUX-TEQ) and all covariates. A $p$-value $<0.05$ was considered as statistical significant.

\section{Results}

Biomarkers of exposure were significantly different between both groups, except for CALUX-TEQ (two-sided Student's $t$-test: $\mathrm{PbB}, p<0.001$; $\mathrm{CdU}, p<0.001 ; \Sigma \mathrm{PCB}$, 
Table 2

NES-results in girls $(n=120)$ and boys $(n=80)$

\begin{tabular}{|c|c|c|c|c|c|c|c|c|c|c|}
\hline \multicolumn{3}{|l|}{ NES-tests ${ }^{\mathrm{a}}$} & \multicolumn{4}{|c|}{$\log \mathrm{PbB}^{\mathrm{b}}$} & \multicolumn{4}{|c|}{$\log \mathrm{CdU}^{\mathrm{b}}$} \\
\hline & Mean & S.D. & $\mathrm{B}$ & S.E. (B) & Beta & $p$-value & $\mathrm{B}$ & S.E. (B) & Beta & $p$-value \\
\hline \multicolumn{11}{|l|}{ Girls } \\
\hline Digit-span forward (number) & 6.25 & 0.89 & - & - & - & $>0.05$ & - & - & - & $>0.05$ \\
\hline Hand-eye coordination (root mean squared error) & 2.18 & 0.35 & - & - & - & $>0.05$ & - & - & - & $>0.05$ \\
\hline Factor-attention & 0.20 & 0.93 & - & - & - & $>0.05$ & - & - & - & $>0.05$ \\
\hline Symbol-digit substitution (s) & 2.32 & 0.26 & - & - & - & $>0.05$ & - & - & - & $>0.05$ \\
\hline \multicolumn{11}{|l|}{ Boys } \\
\hline Digit-span forward (number) & 6.57 & 0.87 & - & - & - & $>0.05$ & - & - & - & $>0.05$ \\
\hline Hand-eye coordination (root mean squared error) & 2.01 & 0.28 & - & - & - & $>0.05$ & - & - & - & $>0.05$ \\
\hline Factor-attention & -0.30 & 1.04 & - & - & - & $>0.05$ & - & - & - & $>0.05$ \\
\hline Symbol-digit substitution (s) & 2.32 & 0.87 & 0.285 & 0.132 & 0.237 & 0.034 & 0.291 & 0.139 & 0.226 & 0.040 \\
\hline
\end{tabular}

${ }^{\text {a }}$ For description of tests and results, see Section 2.

b Stepwise multiple linear regression analysis (see Section 2; B = coefficient; S.E. $(B)=$ standard error $(B)$; Beta = partial correlation coefficient).

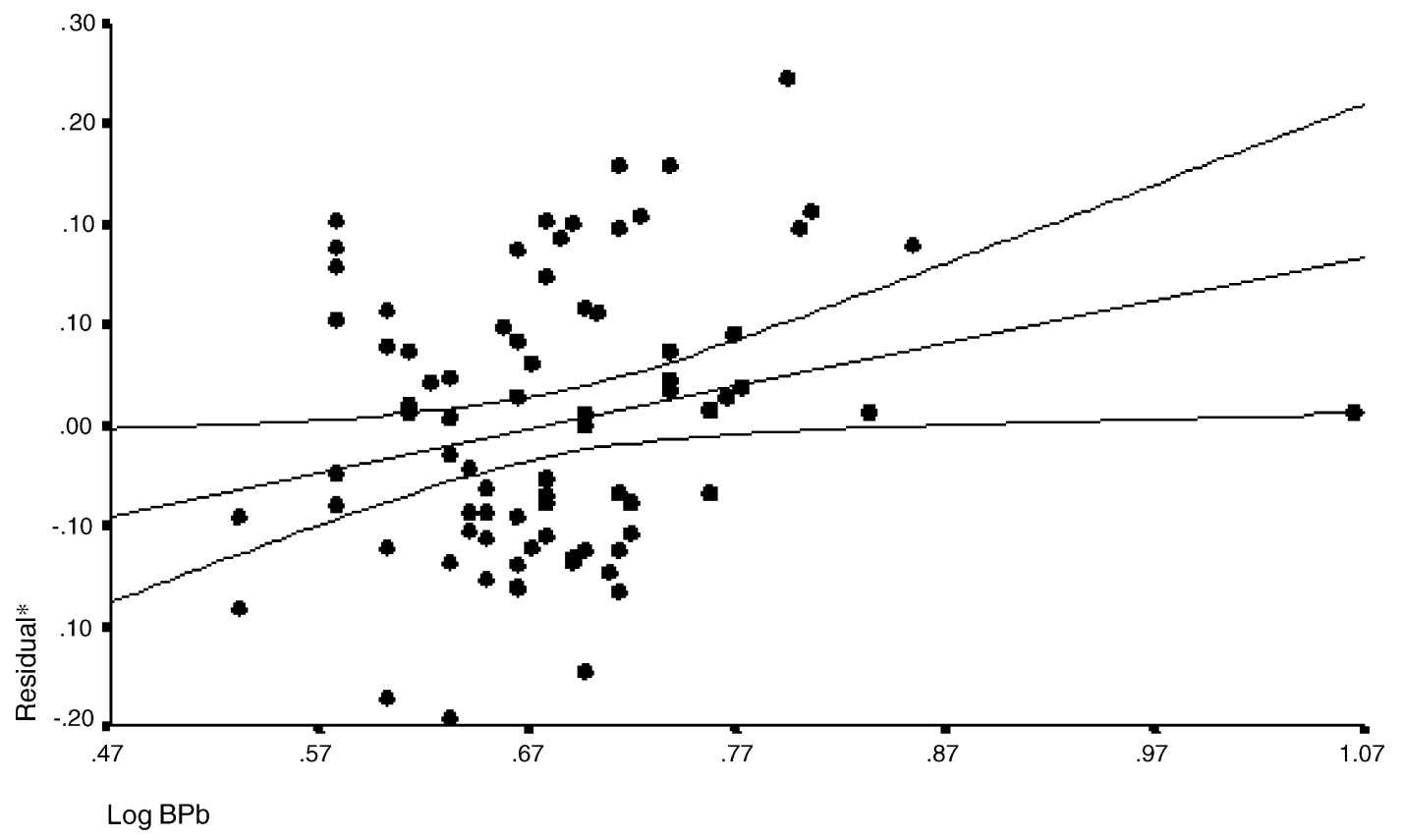

Fig. 1. Symbol-digit substitution results in relation to $\log \mathrm{PbB}$ in boys. $r^{2}=0.06, p=0.03$. $*$ Residuals were calculated after introducing the covariates (educational level of the adolescent, educational level of the mother, social class, living in the family of origin or not, birth order of the child, birth weight, complications during pregnancy/prematurity, tobacco/alcohol consumption during pregnancy, illicit drug use/alcohol abuse, smoking, and body mass index) in a stepwise multiple regression analysis.

$p<0.001)$. Exposure parameters were higher in boys than in girls, except for CdU (Table 1). In boys the upper range of $\mathrm{PbB}$ reached $1542.82 \mathrm{nmol} / \mathrm{L}(32.1 \mu \mathrm{g} / \mathrm{dL})$, while in girls this was four times lower $(363.08 \mathrm{nmol} / \mathrm{L}$ or $7.5 \mu \mathrm{g} / \mathrm{dL}){ }^{1}$

No significant correlations were found between the results of $\mathrm{PbB}$ and $\mathrm{CdU}$. Also no significant correlations were present between $\mathrm{PbB}$ and CALUX-TEQ or $\Sigma \mathrm{PCB}$, and between CdU and CALUX-TEQ or $\Sigma$ PCB. A moderate correlation was seen between $\Sigma$ PCB and CALUX-TEQ $\left(r^{2}=0.06\right.$, $p=0.001$ ).

\footnotetext{
${ }^{1}$ Conversion factors: $1 \mathrm{nmol} \mathrm{Pb}=207.2 \mathrm{ng} \mathrm{Pb}, 1 \mathrm{nmol} \mathrm{Cd}=112.4 \mathrm{ng} \mathrm{Cd}$.
}

Stepwise multiple linear regression analysis showed no relations between the neurobehavioural outcome variables and $\Sigma$ PCB or CALUX-TEQ in breastfed or non-breastfed girls or boys (all $p>0.05$ ). A slowing of performance on SDS with increasing $\mathrm{PbB}\left(r_{\mathrm{P}}^{2}=0.06, p=0.03\right)$ and $\mathrm{CdU}$ concentrations $\left(r_{\mathrm{P}}^{2}=0.05, p=0.04\right)$ was found in the boys' group, but not in the girls' group (Table 2, Figs. 1 and 2). No other outcome variable (HEC, Factor Attention and DSF) was significantly associated with $\mathrm{PbB}$ or $\mathrm{CdU}$.

However, in multiple stepwise linear regression analysis relations were found between the neurobehavioural test results and some covariates. Higher educational level of 


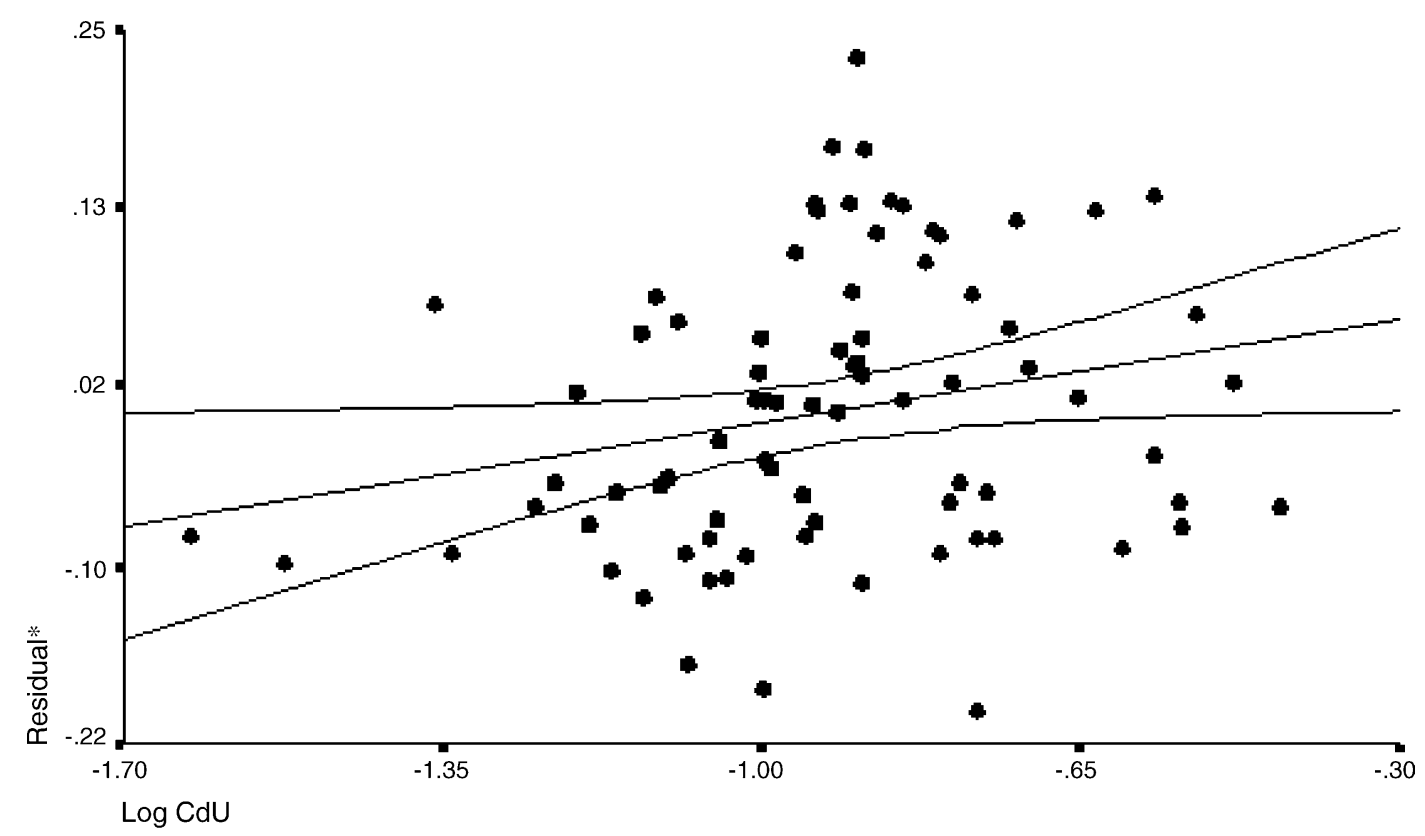

Fig. 2. Symbol-digit substitution results in relation to $\log \mathrm{CdU}$ in boys. $r^{2}=0.05, p=0.04$. $*$ Residuals were calculated after introducing the covariates (educational level of the adolescent, educational level of the mother, social class, living in the family of origin or not, birth order of the child, birth weight, complications during pregnancy/prematurity, tobacco/alcohol consumption during pregnancy, illicit drug use/alcohol abuse, smoking, and body mass index) in a stepwise multiple regression analysis.

the adolescent $\left(r_{\mathrm{P}}^{2}=0.03, p=0.050\right)$ and higher birth weight $\left(r_{\mathrm{P}}^{2}=0.05, p=0.012\right)$ were related to a better performance on the SDS test in girls, but not in boys. In addition, DSF results were positively associated with the educational level of the adolescent in both groups (girls $r_{\mathrm{P}}^{2}=0.17, p<0.001$; boys $r_{\mathrm{P}}^{2}=0.07, p=0.013$ ). Only in girls, performance on the attention tests (Factor Attention) was better for higher social class $\left(r_{\mathrm{P}}^{2}=0.04, p=0.032\right)$, higher educational level of the adolescent $\left(r_{\mathrm{P}}^{2}=0.06, p=0.004\right)$, and living in the family of origin $\left(r_{\mathrm{P}}^{2}=0.08, p=<0.001\right)$. No significant relations between HEC results and the covariates were found in girls, but in boys HEC results were negatively influenced by illicit drug use/alcohol abuse $\left(r_{\mathrm{P}}^{2}=0.06, p=0.031\right)$. With the other covariates (i.e. educational level of the mother, birth order of the child, complications during pregnancy/prematurity, tobacco/alcohol consumption by the mother during pregnancy, smoking, and body mass index) no associations were found in the two study groups.

\section{Discussion}

FLEHS focused on biomonitoring of life time exposures (PbB, CdU, $\Sigma$ PCB and CALUX-TEQ levels in serum) in boys and girls from two different regions of Flanders and possible associated health effects. Place of residence and other environmental factors (smoking habits, food supplies, intake of milk and fat, and duration of breastfeeding) explained $10.8 \%$ of the variance of $\Sigma$ PCB in serum (Nawrot et al., 2002). Also for exposure to heavy metals, it is known from literature that $\mathrm{CdU}$ is significantly influenced by the diet and smoking and $\mathrm{PbB}$ levels by diet and traffic emissions (Feldman, 1999).

In this study, an increasing body burden of both heavy metals seems to impair SDS test results in boys. The restriction of this finding to the boys' group may partly be explained by the higher mean exposure and range of $\mathrm{PbB}$ in boys compared to girls (e.g. for $\mathrm{PbB}$ upper range is higher than $10 \mu \mathrm{g} / \mathrm{dL}$, while in girls the upper range is below $10 \mu \mathrm{g} / \mathrm{dL}$ ). For CdU, however, boys did not show higher values. Otherwise, it could be a gender-specific effect. Gender-specific effects of $\mathrm{Pb}$ exposure have been previously reported (Burns et al., 1999; Tong et al., 2000). In contrast to our findings, Tong et al. (2000) described a more prominent decline of IQ points per $\log$ unit of PbB in 11-13-year-old girls compared to boys. However, this remains a matter of controversy, as the excess of neurotoxicity in girls largely disappeared after adjustment for socio-economic status (Tong et al., 2000). Burns et al. (1999) described higher externalizing behavioural problem scores in boys and more internalizing behaviour problem scores in girls.

That only the SDS test results showed a significant slowing related to the $\mathrm{Pb}$ and $\mathrm{Cd}$ body burdens in boys, may be due to the fact that SDS is a very sensitive test. It is thought to be one of the most discriminative tests to distinguish early dementias or other chronic organic brain disorders (Lezak, 1995; Masur et al., 1994). The test requires integration of visuomotor functions, attention, coding and perceptual organisation, and incidental learning. Moreover, diminished visuomotor 
skills are frequently reported in relation to $\mathrm{Pb}$ and $\mathrm{Cd}$ exposure in children (Feldman, 1999; Stellern et al., 1983; Tatcher et al., 1982). Slowed performance on SDS was also reported to be significantly related to higher Cd levels in adults (Hart et al., 1989; Viaene et al., 2000).

Although our model confirmed several important covariates, e.g. educational level of the adolescent, birth weight, illicit drug use/alcohol abuse, social class and living in the family of origin, our test results may still be biased as other covariates were not taken into account, e.g. the HOMEinventory. But, to our knowledge, it is not known if the quality of the care-giving environment is still relevant at the age of late adolescence or early adulthood for the NES tests used in our study. For instance, the HOME inventory, which is frequently used to measure this factor, is only validated till the age of 15 years.

In our study no dose-effect relation was found between any of the neurobehavioural test results and serum PCB concentrations at the age of 17. This was expected. Firstly, it has been shown previously that only PCB concentrations in maternal serum or umbilical cord blood of non-breastfed preschool children (prenatal exposures) could be linked to the neurobehavioural impairments like diminished mental and motor development and global IQ (Patandin et al., 1999; Vreugdenhil et al., 2002a; Walkowiak et al., 2001; Boersma and Lanting, 2000). Although, these impairments were reported to be measurable till the age of 11 (Jacobson and Jacobsen, 1996), they seem to diminish with age especially if a positive home environment is present (Walkowiak et al., 2001; Vreugdenhil et al., 2002a). However, Walkowiak et al. (2001) reported that postnatal exposures, which are higher in the breastfed group, might be responsible for some of the developmental delay at the age of 42 months. Secondly, our sample size for the analysis with the PCB exposure parameters is rather small due to the additional division in breastfed and non-breastfed groups, which accounts for a loss of power.

\section{Summary}

These results suggest that low to moderate exposures to heavy metals $(\mathrm{Pb}, \mathrm{Cd})$ in industrialized Western-European communities like Flanders may be linked to small but measurable effects on visuomotor skills. A performance decrease was however found in only one of the several tests, i.e. SDS, and only in male adolescents. Further studies are certainly needed to clarify whether this may be a gender-specific effect or whether this is related to the different exposure characteristics in our study groups of boys and girls.

\section{Acknowledgments}

This research was supported by the Flemish Ministry of Health (Brussels, Belgium). We thank the school directorates and the schoolchildren for collaboration. We are much obliged to S. Van Hulle and her co-workers for the coordination of the field work.

\section{References}

Boersma, E.R., Lanting, C.I., 2000. Environmental exposure to polychlorinated biphenyls (PCBs) and dioxins. Consequences for long-term neurological and cognitive development of the child lactation. Adv. Exp. Med. Biol. 478, 271.

Burns, J.M., Baghurst, P.A., Sawyer, M.G., McMichael, A.J., Tong, S.L., 1999. Life-time low-level exposure to environmental lead and children's emotional and behavioral development at ages 11-13 years. The Port Pirie cohort study. Am. J. Epidemiol. 149, 740.

Canfield, R.L., Henderson Jr., Cr., Cory-Slechta, D.A., Cox, C., Jusko, T.A., Lanphear, B.P., 2003. Intellectual impairment in children with blood lead concentrations below 10 microg per deciliter. N. Engl. J. Med. 348 (16), 1517.

Den Hond, E., Roels, H.A., Hoppenbrouwers, K., Nawrot, T., Thijs, L., Vandermeulen, C., Winneke, G., Vanderschueren, D., Staessen, J.A., 2002. Sexual maturation in relation to polychlorinated aromatic hydrocarbons: Sharpe and Skakkebaek's hypothesis revisited. Environ. Health Perspect. 110, 771.

Emmen, H.H., Hoogendijk, E.M.G., Hooisma, J., Orlebeke, J.F., Uijtdehaage, S.H.J., 1998. Adaptation of two standardized international test batteries for use in the Netherlands for detection of exposure to neurotoxic compounds. MBL-TNO report, Delft, The Netherlands.

Fastabend, A., 2000. Bestimmung umweltbedingter Konzentrationen von PCB und Organochlor-pestiziden in Blut mit GC-ECD unter Anwendung optimierter Probenvorbereitungsverfahren. Ph.D. thesis, University of Clausthal, Clausthal, Germany.

Feldman, R.G., 1999. Occupational and Environmental Neurotoxicology. Lippicott-Raven Publishers, Philadelphia, p. 30.

Gilioli, R., 1993. EURONEST: a concerted action of the European community for the study of organic solvent neurotoxicity. Environ. Res. $62,89$.

Hansen, L.G., 1998. Stepping backward to improve assessment of PCB congener toxicities. Environ. Health Perspect. 106 (Suppl. 1), 171.

Hart, R.P., Rose, C.S., Hamer, R.M., 1989. Neuropsychological effects of occupational exposure to cadmium. J. Clin. Exp. Neuropsychol. 11, 933.

Jacobson, J.L., Jacobsen, S.W., 1996. Intellectual impairment in children exposed to polychlorinated biphenyls in utero. N. Engl. J. Med. 335, 783.

Koppen, G., Covaci, A., Van Cleuvenbergen, R., Schepens, P., Winneke, G., Nelen, V., Schoeters, G., 2001. Comparison of CALUX-TEQ values with $\mathrm{PCB}$ and $\mathrm{PCDD} / \mathrm{F}$ measurements in human serum of the Flanders Environment and Health Study (FLEHS). Toxicol. Lett. 123, 59.

Letz, R., 1991. Use of computerized test batteries for quantifying neurobehavioral outcomes. Environ. Health Perspect. 90, 195.

Lewis, M., Worobey, J., Ramsay, D.S., McCormack, M.K., 1992. Prenatal exposure to heavy metals: effect on childhood cognitive skills and health status. Pediatrics 6, 1010.

Lezak, M.D., 1995. Neuropsychological Assessment, third ed. Oxford University Press Inc., New York, p. 352.

Masur, D.M., Sliwinski, M., Lipton, R.B., Blau, A.D., Crystal, H.A., 1994. Neuropsychological prediction of dementia and the absence of dementia in healthy elderly persons. Neurology 44, 1427.

Murk, A.J., Legler, J., Denison, M.S., Giesy, J.P., van de Guchte, C., Brouwer, A., 1996. Chemical-activated luciferase gene expression (CALUX): a novel in vitro bioassay for Ah receptor active compounds in sediments and pore water. Fundam. Appl. Toxicol. 33, 149. 
Nawrot, T.S., Staessen, J.A., Den Hond, E.M., Koppen, G., Schoeters, G., Fagard, R., Thijs, L., Winneke, G., Roels, H.A., 2002. Host and environmental determinants of polychlorinated aromatic hydrocarbons in serum of adolescents. Environ. Health Perspect. 110, 583.

Patandin, S., Lanting, C.I., Mulder, P.G., Boersma, E.R., Sauer, P.J., Weisglas-Kuperus, N., 1999. Effects of environmental exposure to polychlorinated biphenyls and dioxins on cognitive abilities in Dutch children at 42 months of age. J. Pediatr. 134, 33.

Pocock, S.J., Smith, M., Baghurst, P., 1994. Environmental lead and children's intelligence: a systematic review of the epidemiological evidence. BMJ 309, 1189.

Safe, D., 1990. Determination of 2,3,7,8-TCDD toxic equivalent factors (TEFs), support for the use of the in vitro ALIII induction assay. Chemosphere 28, 791.

Staessen, J.A., Nawrot, T., Hond, E.D., Thijs, L., Fagard, R., Hoppenbrouwers, K., Koppen, G., Nelen, V., Schoeters, G., Vanderschueren, D., Van Hecke, E., Verschaeve, L., Vlietinck, R., Roels, H.A., 2001. Renal function, cytogenetic measurements, and sexual development in adolescents in relation to environmental pollutants: a feasibility study of biomarkers. Lancet 357, 1660.

Stellern, J., Marlowe, M., Cossairt, A., 1983. Low lead and cadmium levels and childhood visual-perception development. Percept. Mot. Skills $56,539$.

Struempler, R.E., Larson, G.E., Rimland, B., 1985. Hair mineral analysis and disruptive behavior in clinically normal young men. J. Learn. Disabil. 18, 609.
Tatcher, R.W., Lester, M.L., McAlaster, R., Horst, R., 1982. Effects of low levels of cadmium and lead on cognitive functioning in children. Arch. Environ. Health 37, 159.

Tong, S., Michael, A.J., Baghurst, P.A., 2000. Interactions between environmental lead exposure and sociodemographic factors on cognitive development. Arch. Environ. Health 55, 330.

Van Den Heuvel, R.L., Koppen, G., Staessen, J.A., Hond, E.D., Verheyen, G., Nawrot, T.S., Roels, H.A., Vlietinck, R., Schoeters, G.E., 2002. Immunologic biomarkers in relation to exposure markers of PCBs and dioxins in Flemish adolescents (Belgium). Environ. Health Perspect. 110,595

Viaene, M.K., Masschelein, R., Leenders, J., Swerts, L.J., Roels, H.A., 2000. Neurobehavioural effects of occupational exposure to cadmium: a cross sectional epidemiological study. Occup. Environ. Med. 57, 19.

Vreugdenhil, H.J., Lanting, C.I., Mulder, P.G., Boersma, E.R., WeisglasKuperus, N., 2002a. Effects of prenatal PCB and dioxin background exposure on cognitive and motor abilities in Dutch children at school age. J. Pediatr. $140,48$.

Vreugdenhil, H.J., Slijper, F.M., Mulder, P.G., Weisglas-Kuperus, N., 2002b. Effects of perinatal exposure to PCBs and dioxins on play behavior in Dutch children at school age. Environ. Health Perspect. 110, A593.

Walkowiak, J., Wiener, J.A., Fastabend, A., Heinzow, B., Kramer, U., Schmidt, E., Steingruber, H.J., Wundram, S., Winneke, G., 2001. Environmental exposure to polychlorinated biphenyls and quality of the home environment: effects on psychodevelopment in early childhood. Lancet 358, 1602. 